\title{
Oxidation of alcohols with hydrogen peroxide in the presence of a new triple-site phosphotungstate
}

\author{
Ying He, Xiaoyun Ma and Ming Lu* \\ College of Chemical Engineering, Nanjing University of Science and Technology, Nanjing \\ 210094, People's Republic of China \\ E-mail: orienthawk@163.com
}

\begin{abstract}
A new clean catalytic process for the selective oxidation of alcohol to ketones has been studied. The catalytic properties were investigated with aqueous hydrogen peroxide under halide- and organic solvent-free conditions. The results show that triethyl( $\{2,4,6$-trimethyl-3,5-bis[(triethylazaniumyl)methyl]phenyl $\}$ methyl)azanium (tribromide) based phosphotungstate complex (TBAP) has excellent catalytic ability to the oxidation reaction of alcohol by hydrogen peroxide with high yield. Moreover this catalyst could be easily recovered by simple workup and reused up without any appreciable loss of its activity.
\end{abstract}

Keywords: Oxidation, hydrogen peroxide, alcohol, triple-site phase transfer catalyst, ketone

\section{Introduction}

The selective aqueous biphasic catalytic oxidation of alcohols to the corresponding carbonyl compounds is of significant importance in the fine chemicals and pharmaceutical industries. Oxidations can be carried out with many different oxidants. Commonly, traditional alcohol oxidation employs the strongest stoichiometric oxidizing agents, such as $\mathrm{PCC}, \mathrm{PDC}, \mathrm{KMnO}_{4}$, $\mathrm{MnO}_{2}, \mathrm{Na}_{2} \mathrm{Cr}_{2} \mathrm{O}_{7}$, TEMPO, $\mathrm{CrO}_{3}$ and so on. ${ }^{1,7}$ These oxidation operations are quite useful in lab, but these oxidants are expensive, hazardous or toxic. Meanwhile toxic solvents are usually used to dissolve oxidizing agents and a large amount of inorganic wastes are produced after workup. Hence, in terms of economical and environment concern, catalytic oxidation processes with inexpensive and environmental-friendly oxidants are extremely valuable.

Dilute hydrogen peroxide is an oxidant of ideal choice. It is cheap, readily available and gives water as the only byproduct. Many systems using aqueous hydrogen peroxide as the 
oxidant and tungsten-based catalysts under phase-transfer catalytic conditions have been reported, such as keggin-type tungstoborate catalyst, ${ }^{8} \mathrm{HPA},{ }^{9}\left[\Pi-\mathrm{C}_{5} \mathrm{H}_{5} \mathrm{~N}\left(\mathrm{CH}_{2}\right)_{15} \mathrm{CH}_{3}\right]_{3} \mathrm{PMo}_{12} \mathrm{O}_{40},{ }_{10}$ sodium

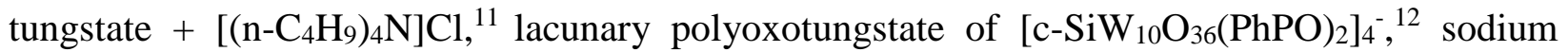
tungstate +quaternaryammoniumhydrogensulfate, ${ }^{13} \quad\left[\mathrm{PW}_{11} \mathrm{O}_{39}\right]^{7-},{ }^{14} \quad\left[\mathrm{NaP}_{5} \mathrm{~W}_{30} \mathrm{O}_{110}\right],{ }^{14-15}$ $\left[\mathrm{HPW}_{9} \mathrm{O}^{34}\right]^{8-},{ }^{16}\left[\mathrm{n}-\mathrm{C}_{16} \mathrm{H}_{33} \mathrm{~N}\left(\mathrm{CH}_{3}\right)_{3}\right]_{3} \mathrm{PW}_{12} \mathrm{O}_{40},{ }^{17}$ and other new methods. ${ }^{18}$ However, based on the fact that most of them may lead to environmental pollution, some poisonous reagents are required as solvents with a time-consuming process and so on. In these contexts, the development of an efficient oxidation of various kinds of alcohols with hydrogen peroxide is still demanded.

Multi-site phase transfer catalysts (MPTCs) containing more than one catalytic active site in a molecule were one of unique class. This type of MPTCs offers the potential of providing great PTC activity and accelerating the particular synthetic transformation even under mild conditions.

Here, we reported a very facile and practical oxidation of alcohols with $\mathrm{H}_{2} \mathrm{O}_{2}$ in presence of TBAP, developed under mild conditions and affording products with high yields in short time (Scheme 1). The major advantage of this method apart from solvent-free conditions is that triple-site phase-transfer catalysis can be prepared easily without using toxic reagents and could be used for the next cycle.

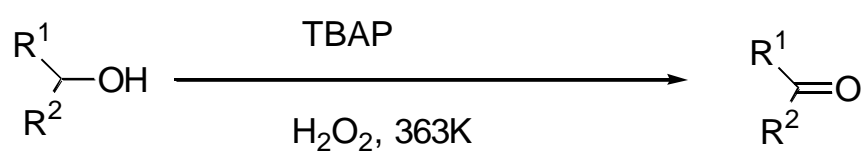

Scheme 1. Oxidation of alcohols with hydrogen peroxide catalyzed by TBAP.

\section{Results and Discussion}

In order to search for an optimum reaction conditions, cyclohexanol is choosed as a model substance. The reaction was carried out with a molar ratio cyclohexanol / TBAP / $30 \% \mathrm{H}_{2} \mathrm{O}_{2} 1$ : 0.001: 1 at $90{ }^{\circ} \mathrm{C}$. Cyclohexanol was oxidized to cyclohexanone in $40 \%$ yield. After some experimentation with respect to the molar ratio of catalyst, we found that the use of 0.005 molar TBAP per mole of the substrate in water consistently produced good yields of cyclohexanone (70\%). However, further increasing the amount of catalyst under the same conditions did not enhance the formation of the cyclohexanone significantly. A blank experiment was also carried out which revealed that in the absence of the TBAP, less than $8 \%$ yield of cyclohexanone was detected.

Having established the importance of the PTC, we switched our attention to the amount of hydrogen peroxide. The excess amount of hydrogen peroxide required is a result of its decomposition at the elevated temperature. The oxygen released in the decomposition reaction plays no role in the oxidation of alcohols. No oxidation occurred under similar conditions but 
using oxygen as oxidant. Thus, we investigated the oxidation with different amounts of $30 \%$ $\mathrm{H}_{2} \mathrm{O}_{2}$ in order to improve the yield. It was obvious that yield was increased from $70 \%$ to $92 \%$ with the 1.5 molar ratio amount of hydrogen peroxide added. However, further addition the amount of $30 \% \mathrm{H}_{2} \mathrm{O}_{2}$ under the same conditions, the yield was not increased significantly. The optimal molar ratio $30 \% \mathrm{H}_{2} \mathrm{O}_{2}$ /substrate is 1.5 .

\section{Catalytic oxidation process}

The proposed catalytic oxidation of alcohols with $\mathrm{H}_{2} \mathrm{O}_{2}$ in presence of TBAP is schematically presented in Figure 2. The solubility of TBAP in water was affected with temperature change. Before the oxidation, there is an oil-water triphasic system, and the bottom layer (aqueous phase) consists of TBAP and hydrogen peroxide. TBAP is completely suspended in aqueous phase, and the upper layer (oil phase) was alcohol. During the oxidation, the oil-water layer disappears and a homogeneous reaction medium is formed. After the completion of the reaction, a complete phase-separation occurred again, after cooling to the room temperature. The TBAP catalytic system has a crucial role in the oxidation process by exhibiting an emulsion dispersion phase behavior. Namely, the emulsion dispersion phase behavior of homogenous phase at high temperature and precipitation at room temperature leads to a large increase in the number of catalytic reactive sites and the excellent reaction yields.

Room temperature

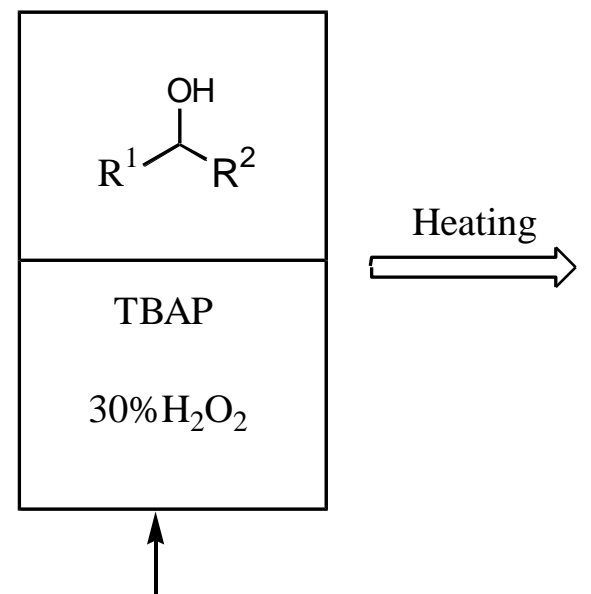

Reaction temperature

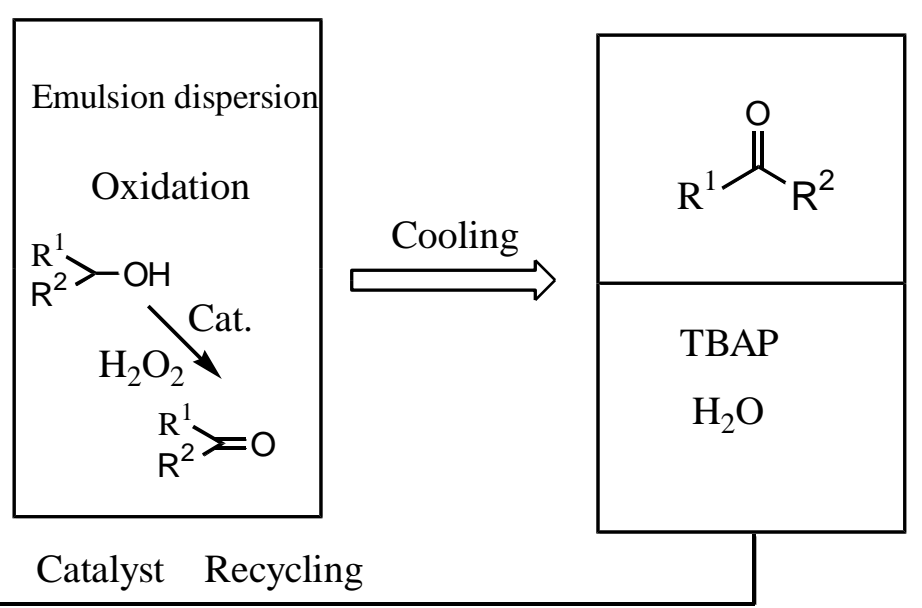

Figure 2. TBAP emulsion dispersion catalytic oxidation process.

From the above research results, the reaction condition was optimized and extended to other primary and secondary alcohols. These results are shown in Table 1. 
Table 1. Oxidation of alcohols to carbonyl compounds ${ }^{\text {a }}$

\begin{tabular}{|c|c|c|c|c|c|c|c|}
\hline Entry & Substrate & Product $^{\mathrm{b}}$ & $\begin{array}{c}\mathrm{H}_{2} \mathrm{O}_{2} / \\
\text { substrat } \\
\text { e molar } \\
\text { ratio }\end{array}$ & $\begin{array}{c}\text { Time } \\
\text { (h) }\end{array}$ & $\begin{array}{c}\text { Conver } \\
\text { sion } \\
(\%)\end{array}$ & $\begin{array}{c}\text { Yield }^{c} \\
(\%)\end{array}$ & $\begin{array}{l}\text { Bp or mp } \\
\left({ }^{\circ} \mathrm{C}\right)(\text { Lit.) }\end{array}$ \\
\hline 1 & $\begin{array}{l}\text { 4-tert-butyl- } \\
\text { cyclohexanol }\end{array}$ & $\begin{array}{l}\text { 4-tert-butyl- } \\
\text { cyclohexanone }\end{array}$ & 1.5 & 2 & 100 & 96 & 95/10Torr ${ }^{13}$ \\
\hline 2 & $\begin{array}{l}\text { 4-Isopropyl- } \\
\text { cyclohexanol }\end{array}$ & $\begin{array}{l}\text { 4-Isopropyl- } \\
\text { cyclohexanone }\end{array}$ & 1.5 & 2 & 100 & 95 & $87 / 12$ Torr $^{19}$ \\
\hline 3 & Cyclohexanol & Cyclohexanone & 1.5 & 2 & 98 & 92 & 85/80 Torr $^{13}$ \\
\hline 4 & $\begin{array}{l}\text { 4-Methyl- } \\
\text { cyclohexanol }\end{array}$ & $\begin{array}{c}\text { 4-Methyl- } \\
\text { cyclohexanone }\end{array}$ & 1.5 & 2 & 100 & 96 & $60 / 12$ Torr $^{20}$ \\
\hline 5 & 2-Butyl alcohol & 2-Butanone & 2 & 1 & 100 & 95 & 80/760Torr ${ }^{19}$ \\
\hline 6 & 1-Phenylethanol & Acetophenone & 1.2 & 1 & 100 & 98 & 78/12Torr ${ }^{13}$ \\
\hline
\end{tabular}


Table 1. Continued

\begin{tabular}{|c|c|c|c|c|c|c|c|}
\hline Entry & Substrate & Product ${ }^{b}$ & $\begin{array}{c}\mathrm{H}_{2} \mathrm{O}_{2} / \\
\text { substrat } \\
\text { e molar } \\
\text { ratio }\end{array}$ & $\begin{array}{c}\text { Time } \\
\text { (h) }\end{array}$ & $\begin{array}{c}\text { Conver } \\
\text { sion } \\
(\%)\end{array}$ & $\begin{array}{l}\text { Yield }^{c} \\
(\%)\end{array}$ & $\begin{array}{l}\text { Bp or mp } \\
\left({ }^{\circ} \mathrm{C}\right)(\text { Lit. })\end{array}$ \\
\hline
\end{tabular}

7

Isopropanol

Acetone

1.5

$1 \quad 100$

$97 \quad 56-57 / 760$ Torr $^{21}$

8

Diphenyl Diphenyl-

carbinol

methanone

1.2

1

100

$98^{\mathrm{d}}$

$107 / 8$ Torr $^{22}$

9

Benzyl alcohol

Benzaldehyde

1.1

1

98

$92^{\mathrm{e}}$

53-54/10 Torr $^{13}$

Benzoic acid

2.5

3

100

93

$121-122^{13}$

10

1-Butanol

Butyraldehyde

2

3

37

20

76/760 Torr $^{23}$

Butyric acid

4

6

56

$43 \quad 60-62 / 10$ Torr $^{24}$

${ }^{\text {a }}$ Reaction conditions: 5 mmol catalyst; 1 mol substrate; 1.5 mol 30\%aq. $\mathrm{H}_{2} \mathrm{O}_{2}$; reaction time $2 \mathrm{~h}$.

${ }^{b}$ All products are known compounds and were identified by comparing their GLC spectra with those of commercially available materials. ${ }^{c}$ Isolated yield. ${ }^{\mathrm{d}}$ Toluene as solvent.e. $5 \% \mathrm{H}_{2} \mathrm{O}_{2}$ was used. 
Table 1 showed representative results for oxidation of aliphatic alcohol and aromatic alcohol to corresponding carbonyl compounds. The aliphatic primary alcohol was difficult to be effectively oxidized to corresponding aldehyde or carboxylic acid and its conversion was very low (entry 10). However, the secondary alcohols were oxidized to ketones in high yield. It was active for oxidation of benzyl alcohol due to the active phenyl group.

\section{Catalyst reusability}

Reusability was initially studied for the oxidation of cyclohexanol as that would give us an insight whether the triple-site active catalyst was available for the second step of oxidation. The results illustrated in Figure 3 showed that the fresh and recycled catalyst had high activities in all runs without any appreciable loss of its activity.

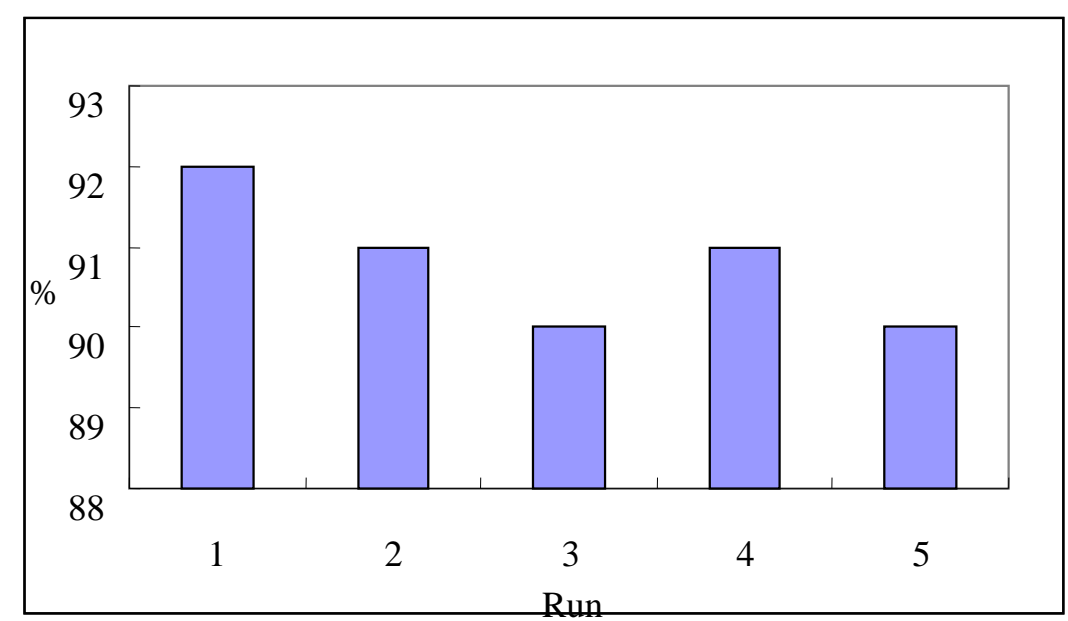

Reaction conditions: 5 mmol catalyst; 1 mol substrate; 1.5 mol 30\%aq. $\mathrm{H}_{2} \mathrm{O}_{2}$; reaction time $2 \mathrm{~h}$.

Figure 3. Reusability of TBAP.

\section{Conclusions}

In summary, we have developed an emulsion dispersion TBAP catalytic system for oxidation of alcohols in water with hydrogen peroxide to corresponding carbonyl compounds in high conversion under halide- and organic solvent-free conditions. The catalytic reactions were quite selective with high yield for oxidations of benzylic and secondary alcohols. The catalyst exhibits high activities in all runs without any appreciable loss of its activity, which is an environmentally 
friendly oxidation system.

\section{Experimental Section}

General. All the alcohols substrates and phase transfer catalysts were commercially available and used without further purification. $85 \% \mathrm{H}_{3} \mathrm{PO}_{4}$, tungstic acid, $30 \% \mathrm{H}_{2} \mathrm{O}_{2}$, triethylamine, acetonitrile, mesitylene, paraformaldehyde, dichloroethane, glacial acetic acid, and hydrobromic acid in acetic acid were obtained from sinopharm chemical reagent company. ${ }^{1} \mathrm{H}$ NMR spectra were recorded with a Bruker DRX-500 spectrometer $\left({ }^{1} \mathrm{H}, 500 \mathrm{MHz}\right)$, and chemical shifts were given on $\delta(\mathrm{ppm})$ scale with tetramethylsilane (TMS) as an internal standard.

Step-1<smiles>Cc1cc(C)cc(C)c1</smiles>

Step-2

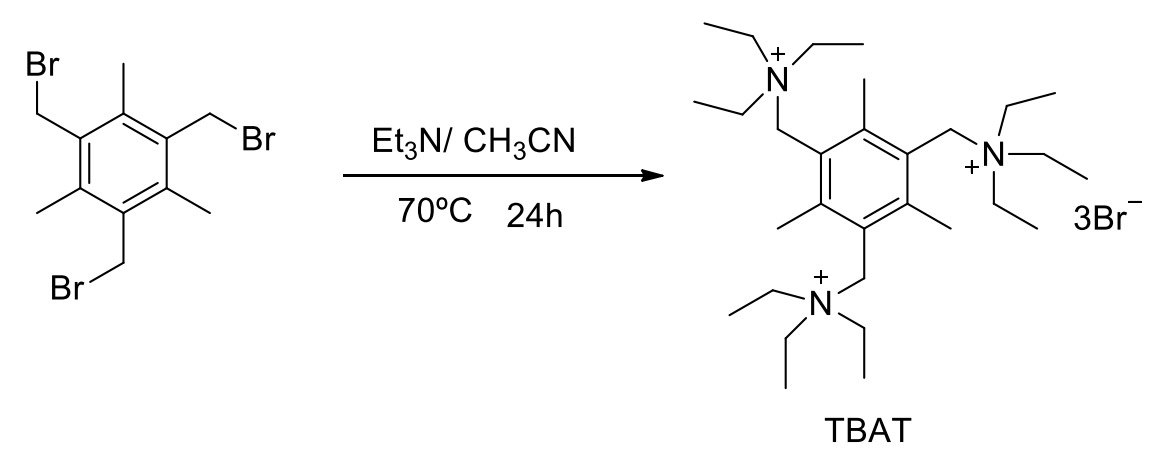

Step-3

$$
\begin{gathered}
4 \mathrm{H}_{2} \mathrm{WO}_{4}+\mathrm{H}_{3} \mathrm{PO}_{4}+8 \mathrm{H}_{2} \mathrm{O}_{2}+\text { TEMABTB } \frac{\mathrm{H}_{2} \mathrm{O}}{\mathrm{CH}_{2} \mathrm{Cl}_{2}} \\
\underset{\text { TEMAB }}{\text { TBAP }}\left[\mathrm{PO}_{4}\left(\mathrm{~W}(\mathrm{O})\left(\mathrm{O}_{2}\right)_{2}\right)_{4}\right]^{3-}+3 \mathrm{HBr}+12 \mathrm{H}_{2} \mathrm{O}
\end{gathered}
$$

Scheme 2. Synthesis of phosphotungstate complex. 
1, 3,5-tri-(Bromomethyl)-2,4,6-trimethylbenzene. To mesitylene (44.5 g, $0.37 \mathrm{~mol})$ and p-formaldehyde (36.6 g, $1.22 \mathrm{~mol})$ was added glacial acetic acid $(185 \mathrm{~mL})$ and hydrobromic acid (33\% in acetic acid, $260 \mathrm{~mL}$ ). The suspension was stirred under nitrogen atmosphere and heated at $95{ }^{\circ} \mathrm{C}$. After $24 \mathrm{~h}$ the reaction mixture was crashed into ice water $(150 \mathrm{~g})$ and stirred vigorously. The formed precipitate was filtered off, washed with water and recrystallized from dichloroethane to give the title product as a white power. Yield: $80 \%$; M.P.: $187-188{ }^{\circ} \mathrm{C}{ }^{1} \mathrm{H}$ NMR (500 MHz, $\left.\mathrm{CDCl}_{3}\right): \sigma 2.46\left(\mathrm{~s}, 9 \mathrm{H}, \mathrm{Ar}_{-} \mathrm{CH}_{3}\right), 4.57\left(\mathrm{~s}, 6 \mathrm{H},-\mathrm{CH}_{2}\right) ;{ }^{13} \mathrm{C} \mathrm{NMR}(100 \mathrm{MHz}$, $\left.\mathrm{CDCl}_{3}\right): \sigma 12.0,27.1,134.68,137.15 .^{25}$

\section{Triethyl $(\{2,4,6-t$ rimethyl-3,5-bis [(triethylazaniumyl)methyl $]$ phenyl $\}$ methyl $)$ azanium(tribro mide) (TBAT)}

The title compound was prepared following the previous literature reported. $.^{25} 1,3$, 5-Tris ( bromomethyl )-2, 4, 6-trimethylbenzene (4 g, $11.8 \mathrm{mmol}$ ) was dissolved in dry acetonitrile (10 $\mathrm{mL})$ and transferred into a $150 \mathrm{~mL}$ three-necked round-bottomed flask. Triethylamine $(4.17 \mathrm{~g}$, $41.29 \mathrm{mmol})$ dissolved in acetonitrile $(15 \mathrm{~mL})$ was added to the solution. The reaction mixture was stirred vigorously under inert atmosphere $\left(\mathrm{N}_{2}\right)$. The reaction was refluxed for $24 \mathrm{~h}$. After completion of the reaction, the mixture was cooled to room temperature to obtain the pale yellowish solid. Yield: 85\%; ${ }^{1} \mathrm{H}$ NMR (500 MHz, DMSO): $\sigma$ 1.08-1.29 (m, 27H, $\left.-\mathrm{CH}_{3}\right), 2.65$ (s, $\left.9 \mathrm{H}, \mathrm{Ar}-\mathrm{CH}_{3}\right), 3.29-3.35\left(\mathrm{~m}, 18 \mathrm{H},-\mathrm{CH}_{2}\right), 4.81\left(\mathrm{~s}, 6 \mathrm{H},-\mathrm{CH}_{2}\right)$.

Synthesis of catalyst TBAP ( phosphotungstate complex ). The catalyst was prepared following the previous literature reported. ${ }^{26}$ Tungstic acid $(5 \mathrm{~g}, 20 \mathrm{mmol})$ was added portion wise to a $30 \%$ solution of $\mathrm{H}_{2} \mathrm{O}_{2}(20 \mathrm{~mL})$ with stirring and heated to $60{ }^{\circ} \mathrm{C}$, and the mixture was stirred for $1 \mathrm{~h}$ until a colorless solution was obtained. $\mathrm{H}_{3} \mathrm{PO}_{4}(0.62 \mathrm{~mL}$ of $80 \%$ sol., calc. $5 \mathrm{mmol})$ was added to the solution at room temperature and the whole was diluted to $60 \mathrm{~mL}$ with water. TBAT (2.34 g, $3.3 \mathrm{mmol}$ ) in $\mathrm{CH}_{2} \mathrm{Cl}_{2}(60 \mathrm{~mL})$ was added dropwise to the above solution. A brownish yellow solid was precipitated with stirring. Filtered and washed with purified water to obtain the phosphotungstate complex solid. Yield: 95\%. IR (neat, KBr plates) the absorption in the region 1106 and 1085 were assigned to P-O stretching vibration. A strong peak at 965 indicated the presence of $\mathrm{W}=\mathrm{O}$, and peaks at $885(\mathrm{O}-\mathrm{O}) .572$ and 489 confirmed the tungstate structure. Absorption at 1636, 1475, 1456 and 1397 is due to phenyl ring (see Figure 4). 


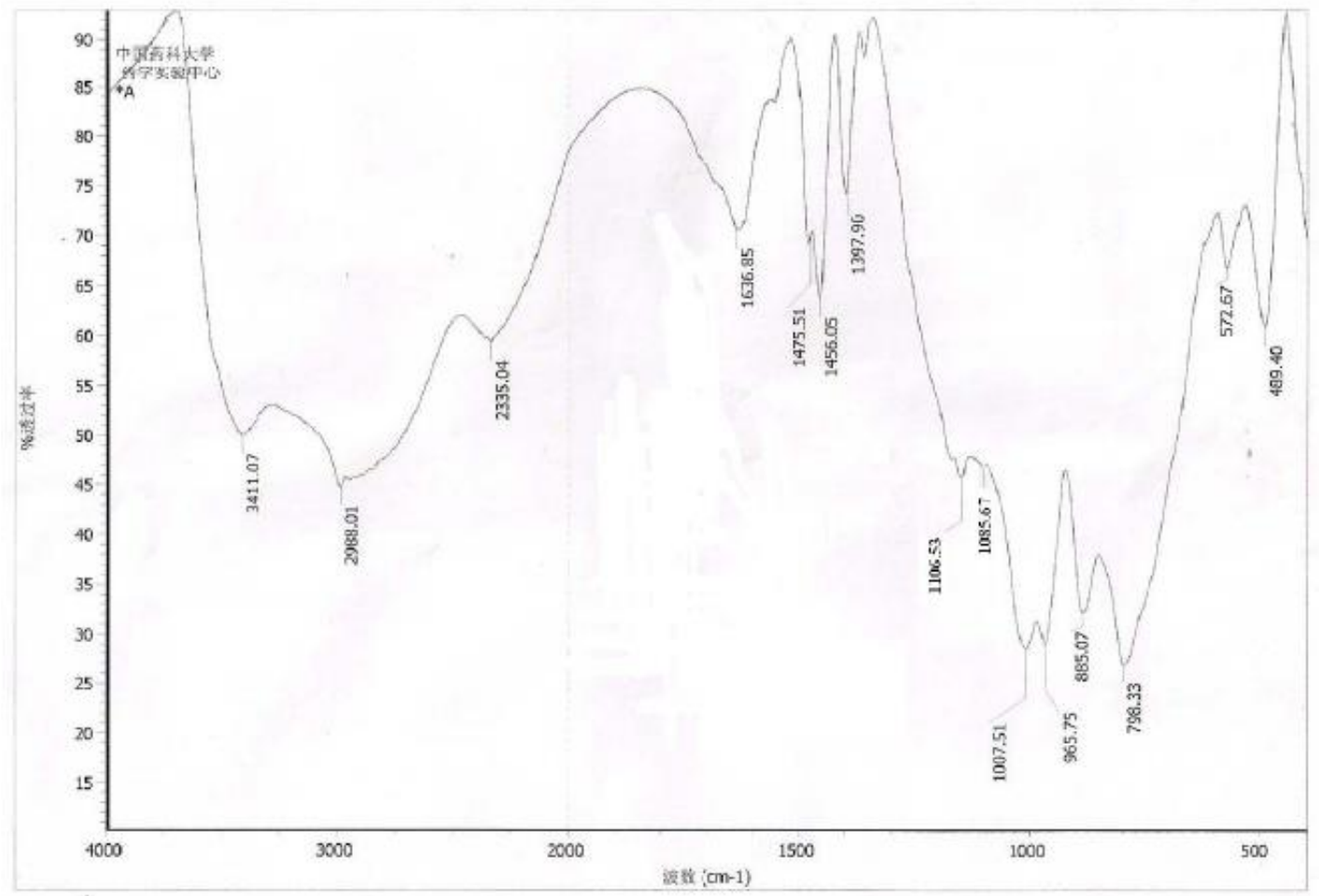

Figure 4. FT-IR spectrum of catalyst.

General procedure of catalytic oxidation experiments. A $500 \mathrm{~mL}$, round-bottomed flask equipped with mechanical agitation and a reflux condenser was charged with $8.06 \mathrm{~g}(5 \mathrm{mmol})$ of catalyst TBAP, $1 \mathrm{~mol}$ of each substrate and $169 \mathrm{~g}(1.5 \mathrm{~mol})$ of aqueous $30 \% \mathrm{H}_{2} \mathrm{O}_{2}$ were added successively. Then, the mixture was heated to $90{ }^{\circ} \mathrm{C} . \mathrm{H}_{2} \mathrm{O}_{2}$ was consumed completely via an inspection with potassium iodide-starch test paper. The conversion of the substrate was monitored by GLC. After a suitable time interval the reaction was stopped and the product was separated, washed with saturated aqueous $\mathrm{Na}_{2} \mathrm{~S}_{2} \mathrm{O}_{3}$ and distilled through a short column under vacuum. After separation of product, the aqueous layer was evaporated under vacuum or filtered by filtration membrane to obtain the catalyst. Readdition of alcohols $(1 \mathrm{mmol})$ and $30 \% \mathrm{H}_{2} \mathrm{O}_{2}$ to flask containing the TBAP was carried out for the next oxidation cycle.

\section{Selected spectroscopic data}

Cyclohexanone (Table 1, entry 3). Colorless oil. ${ }^{1} \mathrm{H} \mathrm{NMR}\left(500 \mathrm{MHz}, \mathrm{CDCl}_{3}\right) \delta$ 1.69-1.76 (m, $2 \mathrm{H}), 1.82-1.90(\mathrm{~m}, 4 \mathrm{H}), 2.31-2.36(\mathrm{t}, 4 \mathrm{H}, J 6.5 \mathrm{~Hz}) .{ }^{13} \mathrm{C} \mathrm{NMR}\left(100 \mathrm{MHz}, \mathrm{CDCl}_{3}\right) \delta 24.80,26.85$, 41.84, 211.90.

Acetophenone (Table 1, entry 6). Colorless oil. ${ }^{1} \mathrm{H}$ NMR (500 MHz, $\left.\mathrm{CDCl}_{3}\right) \delta 2.6(\mathrm{~s}, 3 \mathrm{H}), 7.45$ $(\mathrm{d}, 2 \mathrm{H}), 7.55(\mathrm{t}, 1 \mathrm{H}, J 8.0 \mathrm{~Hz}), 7.94(\mathrm{~d}, 2 \mathrm{H}, J 7.5 \mathrm{~Hz}) .{ }^{13} \mathrm{C} \mathrm{NMR}\left(100 \mathrm{MHz}, \mathrm{CDCl}_{3}\right) \delta 26.80$, $128.25,128.51,134.10,137.11,198.12$. 
Benzaldehyde (Table 1, entry 9). Colorless oil. ${ }^{1} \mathrm{H}$ NMR (500 MHz, $\left.\mathrm{CDCl}_{3}\right)$ : $\delta: 7.48-7.57$ (dd, 2H, J 7.5, 7.8 Hz), 7.59-7.67 (dt, 1H, J 1.6, 7.5 Hz), 7.82-7.87 (dd, 2H, J 1.6, 7.5 Hz), 10.00 (s, $1 \mathrm{H}){ }^{13} \mathrm{C}$ NMR $\left(100 \mathrm{MHz}, \mathrm{CDCl}_{3}\right) \delta: 128.95,129.75,134.46,136.48,192.40$.

\section{Acknowledgements}

We thank the National Basic Research Program (973) of China (No. 613740101) and Natural Science Foundation of Jiangsu Province for support of this research.

\section{References}

1. Holum, J. R. J. Org. Chem. 1961, 26, 4814.

2. Collins, J. C.; Hess, W. W.; Frank, F. J. Tetrahedron Lett. 1968, 9, 3363.

3. Corey, E. J.; Suggs, J. W. Tetrahedron Lett. 1975, 16, 2647.

4. Highet, R. J.; Wildma, W. C. J. Am. Soc. Chem. 1955, 77, 4399.

5. Lee, D. G.; Spitzer, U. A. J. Org. Chem. 1970, 35, 3589.

6. Stevens, R. V.; Chapman, K. T.; Weller, H. N. J. Org. Chem. 1980, 45, 2030.

7. Menger, F. M.; Lee, C. J. Org. Chem. 1979, 44, 3446.

8. Zhao, W.; Zhang, Y. Catal. Commun. 2010, 1, 527.

9. Pietro, T.; Gustavo, P. Catal. Commun. 2010, 11, 1181.

10. Ishii, Y. K.; Yamawaki, T.; Yoshida, T. J. Org. Chem. 1987, 52, 1868.

11. Gresley, N. M.; Griffith, W. P.; Laemmel, A. C.; Nogueira, H. I. S.; Parkin, B. C. J. Mol. Catal. 1997, 117, 185.

12. Carraro, M.; Sandei, L.; Sartorel, A.; Scorrano, G.; Bonchio, M. Org. Lett. 2006, 8, 3671.

13. (a) Sato, K.; Hyodo, M.; Aoki, M.; Zheng, X. Q.; Noyori, R. Tetrahedron 2001, 57, 2469. (b) Sato, K.; Aoki, M.; Takagi, J.; Noyori, R. J. Am. Chem. Soc. 1997, 119, 12386. (c) Sato, K.; Aoki, M.; Takagi, J.; Zimmermann, K.; Noyori, R. Bull. Chem. Soc. Jpn. 1999, 72, 2287.

14. Weng, Z. H.; Wang, J. Y.; Jian, X. G. Catal. Commun. 2008, 9, 1688.

15. Bamoharram, F. F.; Roshani, M.; Heravi, M. M.; Safaie, S. Phosphorus, Sulfur Silicon Relat. Elem. 2006, 181, 2833.

16. Zhao, Wei; Ding, Yong; Ma, Baochun and Qiu, Wenyuan. Synth. Commun. 2012, 42, 554.

17. Zhang, Shengjun; Zhao, Gongda; Gao, Shuang; Xi, Zuwei, Xu, Jie J. Mol. Catal. A: Chem. 2008, 289, 22.

18. Sheldon, R. A.; Arends, I. W. C. E.; Dijksman, A. Catal. Today 2000, 57, 157. 
19. Soffer, M. D. J. Am. Chem. Soc. 1955, 77, 1003.

20. Moiseenkov, A. M. Zhurnal. Organicheskoi. Khimii. 1987, 23, 1852.

21. John, H. J. Chem. Soc., Dalton Trans. 1909, 95, 1919.

22. Hamrick, P. J. J. Am. Chem. Soc. 1959, 81, 3144.

23. Santaniello, E. Synthesis 1980, 7, 563.

24. Blanc, P.Y. Helvetica Chim. Acta 1964, 47, 567.

25. Vivekanand, P. A.; Balakrishnan, T. Catal. Commun. 2009, 10, 1962.

26. Venturello, C.; D'Aloisio, R. J. Org. Chem. 1988, 53, 1553. 